\title{
Linkage disequilibrium and genome-wide association analysis for anthocyanin pigmentation and fruit color in eggplant
}

Fabio Cericola ${ }^{1,2}$, Ezio Portis ${ }^{1 *}$, Sergio Lanteri ${ }^{1}$, Laura Toppino ${ }^{2}$, Lorenzo Barchi ${ }^{1}$, Nazzareno Acciarri ${ }^{3}$, Laura Pulcini ${ }^{3}$, Tea Sala ${ }^{2}$ and Giuseppe Leonardo Rotino ${ }^{2}$

\begin{abstract}
Background: The genome-wide association (GWA) approach represents an alternative to biparental linkage mapping for determining the genetic basis of trait variation. Both approaches rely on recombination to re-arrange the genome, and seek to establish correlations between phenotype and genotype. The major advantages of GWA lie in being able to sample a much wider range of the phenotypic and genotypic variation present, in being able to exploit multiple rounds of historical recombination in many different lineages and to include multiple accessions of direct relevance to crop improvement.
\end{abstract}

Results: A 191 accessions eggplant (Solanum melongena L.) association panel, comprising a mixture of breeding lines, old varieties and landrace selections originating from Asia and the Mediterranean Basin, was SNP genotyped and scored for anthocyanin pigmentation and fruit color at two locations over two years. The panel formed two major clusters, reflecting geographical provenance and fruit type. The global level of linkage disequilibrium was $3.4 \mathrm{cM}$. A mixed linear model appeared to be the most appropriate for GWA. A set of 56 SNP locus/phenotype associations was identified and the genomic regions harboring these loci were distributed over nine of the 12 eggplant chromosomes. The associations were compared with the location of known QTL for the same traits.

Conclusion: The GWA mapping approach was effective in validating a number of established QTL and, thanks to the wide diversity captured by the panel, was able to detect a series of novel marker/trait associations.

\section{Background}

Eggplant (Solanum melongena L.) ranks third in commercial importance among the solanaceous crops after potato and tomato, and it is cultivated in many countries, particularly in southern Asia, middle East and Northern Africa. Global production in 2012 was about $48 \mathrm{Mt}$ [1], and the largest European producer is Italy. Despite its commercial importance, little research effort has been devoted to the genetic analysis of key breeding and quality traits with respect to the other Solanaceae crops tomato, potato and Capiscum [2-4]. Several quantitative trait loci (QTL) underlying fruit color and shape have been described by Nunome et al. [5], while

\footnotetext{
*Correspondence: ezio.portis@unito.it

'Dipartimento di Scienze Agrarie, Forestali e Alimentari (DISAFA) - Plant Genetics and Breeding, University of Torino, Largo P. Braccini 2, I-10095 Grugliasco, Torino, Italy

Full list of author information is available at the end of the article
}

Doganlar et al. [6] and Frary et al. [7] succeeded in identifying QTL for certain fruit- and plant-related traits, but only in a population derived from an inter-specific cross, which is of reduced utility in eggplant improvement. More recently, the genetic basis of parthenocarpy [8], Ralstonia solanacearum resistance [9], anthocyanin content [10] and a group of agronomic traits [11] has been elucidated.

The genome-wide association (GWA) approach represents an alternative to biparental linkage mapping for the determination of the genetic basis of traits [12]. Both approaches rely on recombination to re-arrange the genome [13], and seek to establish correlations between phenotype and genotype, based on the non-random association of alleles at two or more loci, termed linkage disequilibrium (LD). In a bi-parental population, only the polymorphisms between the two parents can be queried, whereas in a GWA population the number of 
polymorphisms is determined by the genetic diversity of the entire germplasm panel. In a GWA population, LD is determined not only by recombination frequency, but also by genetic drift, by the mating system of the plant and by the history of selection (reviewed by Rafalski and Morgante [14]). The major advantages of GWA over biparental linkage mapping lie in the much wider variability in phenotype and genotype made accessible, a history of multiple rounds of recombination in many different lineages and the inclusion of germplasm of direct relevance to crop improvement. The real risk that the genetic architecture of the germplasm panel may cloud the analysis has to be allayed by a prior evaluation of the population's structure [15].

To date only one GWA-based study of variation in eggplant has been performed [16] but the present study used a larger number of accessions (191 vs 141) and a more densely populated genetic map (384 SNPs (single nucleotide polymorphisms) vs 105 microsatellites) and targeted traits related to anthocyanin accumulation and fruit color.

\section{Methods}

\section{Plant material and DNA isolation}

A core set of 191 accessions (Additional file 1: Table S1), chosen from a large collection of breeding lines, old varieties and landrace selections by Cericola et al. [17], was established to represent germplasm grown in east Asia (EA accessions) and in the Mediterranean basin (WE). The entries were all highly homozygous and thus phenotypically stable. Genomic DNA was extracted from fresh young leaves harvested from three individuals of each accession, using an E.Z.N.A. ${ }^{\mathrm{rm}}$ Plant DNA mini kit (OMEGA Bio-Tek, Norcross, GA, USA), according to the manufacturer's protocol. The quality of each DNA sample was monitored by electrophoresis through an $0.8 \%$ agarose gel and its DNA concentration estimated spectrophotometrically (DU730, Beckman Coulter Brea CA, USA).

\section{SNP data acquisition}

Each accession was genotyped at 384 SNP loci as reported by Barchi et al. [18]; 339 of these have been genetically mapped [10]. SNPs were selected taking into account a quality score, based on the probability of good performance using the Illumina Golden Gate assay (Illumina, San Diego, CA, USA); the score $>0.6$ indicates a high probability of success. A BlastX search was carried out against the TAIR9 dataset using the 2,201 highest quality score SNPs as query; the 384 sequences having the highest e-value were then chosen. The GoldenGate assay was carried out at the UC Davis Genome Center (www.genomecenter. ucdavis.edu). Automatic allele calling was handled by GenCall software (Illumina). Two of the entries were included in duplicate as an internal control. SNP loci in which the minimum allele frequency (MAF) fell below 5\%, along with those where $>10 \%$ of the data were missing, were discarded. Each SNP locus was scored as a binary data point, and the PIC (polymorphism information content) of each was estimated following Anderson et al. [19].

\section{Population structure}

Genetic similarities between pairs of entries were quantified by the Dice [20] similarity index, then used to describe genetic relationships using both the unweighted pair-group arithmetic mean (UPGMA) method, and principal coordinate analysis (PCoA) by means of Past 2.08 software [21]. STRUCTURE v2.1 software [22] was used to estimate the number of sub-populations in the panel, applying the admixture model for the ancestry of individuals and correlated allele frequencies. The population structure was modelled with a burn-in of 50,000 cycles followed by 100,000 Markov Chain Monte Carlo (MCMC) repeats. The Evanno et al. [23] transformation method was then used to infer $K$, the most likely number of populations. Pair-wise kinship coefficients between the accessions were estimated using SPAGeDi software [24]. The diagonal of the matrix was set to two, and negative values were set to 0, following $\mathrm{Yu}$ et al. [15].

\section{LD analysis}

LD decay was quantified by plotting pair-wise $r^{2}$ values against the distance (cM) between adjacent SNP loci, based on the genetic map developed by Barchi et al. [10]. The effect of population structure on LD was investigated with three approaches as suggested by Mangin et al. [25]: $\mathrm{r}^{2}$ (an estimate of LD between SNP loci without any correction); $r_{s}^{2}$ (taking into account population structure derived from STRUCTURE analysis) and $\mathrm{r}_{\mathrm{sv}}^{2}$ (taking into account both the STRUCTURE output and the kinship matrix). To quantify the reach of LD, an $\mathrm{r}^{2}$ threshold of 0.15 was set [26]. The relationship between the baseline $r^{2}$ values and genetic distance was determined using a locally weighted scatter plot smoothing line [27]. To visualize LD throughout the genome, heat maps were produced based on pair-wise $r^{2}, r_{s}^{2}$ and $r_{s v}^{2}$ values [28]. The estimation of all LD measures was carried out by programs implemented in the $R$ package LDcorSV [25].

\section{Acquisition and analysis of phenotypic and morphological data}

The accessions were grown in field both at Montanaso Lombardo (ML: $45^{\circ} 20^{\prime} \mathrm{N}, 9^{\circ} 26^{\prime} \mathrm{E}$ ) and at Monsampolo del Tronto (MT: $42^{\circ} 53^{\prime} \mathrm{N}$; $13^{\circ} 47^{\prime} \mathrm{E}$ ) in 2010 and again in 2011. In each trial, the material was set out as two randomized complete blocks with six plants per entry per block, and standard horticultural practices were applied. Phenotyping methodology was based on the European 
Cooperative Programme for Plant Genetic Resources Solanaceae descriptors (ECPGR [29]) and the International Board for Plant Genetic Resource descriptors for eggplant (IBPGR [30]). The traits assayed were adaxial leaf lamina anthocyanin (adlan), stem anthocyanin (stean), abaxial leaf lamina anthocyanin (ablan), calyx anthocyanin (calan), corolla color (corcol), adaxial leaf venation anthocyanin (adlvean), abaxial leaf venation anthocyanin (ablvean), peduncle anthocyanin (pedan), fruit color $(f \mathrm{col})$ and fruit glossiness $(f g l o)$. The anthocyanin content of the vegetative part of the plant was scored on a $0-5$ scale, with "0" representing no visible anthocyanin pigmentation (completely green tissue), and " 5 " representing dark violet tissue. corcol was scored as "0" for white, "1" for pink and "2" for violet. fcol was measured using a CR-400 Chroma-meter (Konica Minolta, Tokyo, Japan) to generate three Hunter color coordinates $\left(\mathrm{L}^{*}, \mathrm{a}^{*}\right.$ and $\left.\mathrm{b}^{*}\right)$, averaged across three regions of the surface on each fruit; the measurements were reduced to a single variable by calculating the Euclidean distance from white $\left(L^{*}=100, a^{*}=0, b^{*}=0\right)$, following Prohens et al. [31]. fglo was scored as "1" for opaque, "2" for intermediate and " 3 " for bright peel color. The trait data were treated as adjusted entry means (best linear unbiased predictors). Several multivariate linear mixed models were tested using a combination of the F-test (for the fixed component) and the Akaike test (for the random component). The model shown to best fit the data was: $p_{i j s b}=l_{j}+y_{s}+r_{b j s}+g_{i}+m_{i j}+n_{i s}+e_{i j s}$, where $p_{i j s b}$ represents the phenotype of the $b^{\text {th }}$ replicate of the $i^{\text {th }}$ genotype at the $j^{t h}$ location in the $s^{t h}$ year; $l_{j}$ represents the fixed effect of the $j^{\text {th }}$ location, $y_{s}$ the fixed effect of the $s^{t h}$ year, $r_{b j s}$ the fixed effect of the $b^{\text {th }}$ replicate within the $j^{\text {th }}$ location in the $s^{\text {th }}$ year, $g_{i}$ the random effect of the $i^{t h}$ genotype, $m_{i j}$ the random effect of the genotype by location interaction, $n_{i s}$ the random effect of the genotype by year interaction and $e$ the residual. Broad-sense heritabilities were calculated from the expression

$$
h^{2}=\frac{\sigma_{g}^{2}}{\sigma_{g}^{2}+\sigma_{y}^{2} / n_{y}+\sigma_{l}^{2} / n_{l}+\sigma_{e}^{2} /\left(n_{y} \times n_{l}\right)}
$$

where $\sigma_{g}^{2}$ represented the genotypic variance, $\sigma_{y}^{2}$ the genotype $\mathrm{x}$ year interaction, $\sigma_{l}^{2}$ the genotype $\mathrm{x}$ location interaction, $\sigma_{e}^{2}$ the residual variance, $n_{y}$ the number of years (2) and $n_{l}$ the number of locations (2). Pearson correlation coefficients were calculated between each pair of phenotypic traits. All analyses were carried out by algorithms implemented in $R$ software [32].

\section{GWA mapping}

The GWA analysis was performed using Tassel v4.0.25 software [33]. Three models were tested: the simple general linear model (GLM, Naive-model), the structured association model (GLM, Q-model), based on the STRUCTURE output, and the mixed linear model (MLM, K + Q-model), taking into account both the STRUCTURE output and the kinship matrix [15]. The mixed-model approach has been used elsewhere [34-36] to analyse variation in qualitative traits by treating them as quantitative ones, on the assumption that averaging across replicates would produce normality. The cumulative density function was applied to assess the efficiency of the various models in correcting for population structure. The false positive rate (p-value) was converted into a false discovery rate [37], using the QVALUE package implemented in $R$. The estimation of the overall proportion of true null hypothesis $\pi 0$ was based on $\lambda$ range set from 0 to 0.95 by 0.05 and the smoother method was applied [38]. q-values $<0.05$ were considered as significant. For each significantly associated SNP locus, a general linear model with all fixed effect terms was applied to estimate the proportion of the phenotypic variance explained (PVE). In order to visualize the associations and to compare them with established QTL $[6,10]$, all SNPs associated with a particular trait mapping within less than double the mean LD stretch were considered as a single unit defining association groups. The resulting genetic map, incorporating the associations and QTL detected here into an F2-based linkage map [10], was drawn using MapChart v2.1 software [39]. Synteny between tomato and eggplant chromosomal regions was investigated by aligning the RAD tag sequences [40] surrounding SNPs against the tomato SL2.40 genome sequence (http://solgenomics.net/) using the Burrows-Wheeler alignment tool [41]. Alignments with a MAPping Quality value $>10$ were considered as valid.

\section{Results}

\section{Genotypic characterization and population structure}

The 191 accessions were initially genotyped at 384 SNP loci, of which 338 were retained after quality control. The two replicated accessions gave uniformly consistent allele calls. MAF at most of the SNP loci ranged from $10 \%$ to $50 \%$ (Additional file 2: Figure S1A), with only 24 displaying a MAF value $<5 \%$. These were discarded, leaving a genotypic matrix of 191 entries by 314 SNP loci, of which 307 have been placed on the Barchi et al. [10] genetic map. The global average PIC value was 0.41 ; loci on chromosome E02 had a low mean PIC value (0.28), while the mean PIC for the remaining loci on a chromsome-by-chromosome basis lay between 0.38 and 0.46 (Additional file 2: Figure S1B).

The STRUCTURE analysis resulted in a prediction for $K$ of either 1 or 2 (Figure 1A). The UPGMA-based dendrogram (Figure 1B) and the PCoA (Figure 1C) show the genetic relationships between the 191 accessions. Their form, as well as the $\Delta \mathrm{K}$ analysis provided by the 
Evanno et al. [23] transformation, suggested a population structure comprising two subgroups. According to the level of membership provided by STRUCTURE, cluster A contained $91 \%$ of the EA accessions, while $96 \%$ of the cluster B membership comprised WA accessions. The remaining 35 accessions (18\%) had ambiguous membership and were thus classified as admixed. PCoAs carried out separately on the EA accessions showed some clustering among the Chinese entries, and among the Indian and SE Asian ones (Additional file 3: Figure S2A). The WA entries were grouped according to previously described morphology-based groups (Additional file 3: Figure S2B) [17], where group 1 accessions produced long, light and curved fruits, group 2 oblong shaped fruits of medium weight and group 3 round, heavy fruits.

\section{LD evaluation}

An $\mathrm{r}^{2}$ threshold of 0.15 was applied to define which SNP loci were significantly associated with one another. On the basis of the $\mathrm{r}^{2}$ model (with no correction for the population structure, Figure 2A), the mean genetic length of these associated groups was $4.8 \mathrm{cM}$. A mean $\mathrm{r}^{2}$ of 0.15 was observed between all pairs of linked loci, with a mean maximum $\mathrm{r}^{2}$ value of 0.56 . The mean LD between unlinked loci was 0.10 . When the $\mathrm{r}_{\mathrm{s}}^{2}$ model was applied (Figure 2B), the $\mathrm{LD}$ stretch was reduced to $3.9 \mathrm{cM}$, with a mean level of 0.07 between adjacent loci; an average of the highest $r_{s}^{2}$ value of each marker with any other of 0.45 , and the mean LD between unlinked loci was 0.02 . On the basis of the $\mathrm{r}_{\mathrm{sv}}^{2}$ model (Figure 2C), $\mathrm{LD}$ extended over $3.4 \mathrm{cM}$, with a whole genome mean of 0.03 between adjacent (maximum 0.26 ) and a mean LD between unlinked loci of less than 0.01 . Heat maps produced for each of the three models showed that strong LD was limited to certain regions, mostly aligned to the diagonal (Figure 3). Apparent high levels of LD between loci mapping to a different chromosome were suggested in the $\mathrm{r}^{2}$ model, but this phenomenon was largely absent in the $r_{s}^{2}$ and $r_{s v}^{2}$ models.

\section{Phenotypic data analysis and association mapping}

A summary of the accessions' phenotypic performance is presented in Table 1 together with the heritabilities for scored traits. The PVEs are included in Additional file 4: Figure S3. A wide range of variation was observed for most of the traits, and the genotypic variance component was substantial for all of them $(\mathrm{P}<0.01)$. pedan, fcol and calan were the most genetically variable of the traits

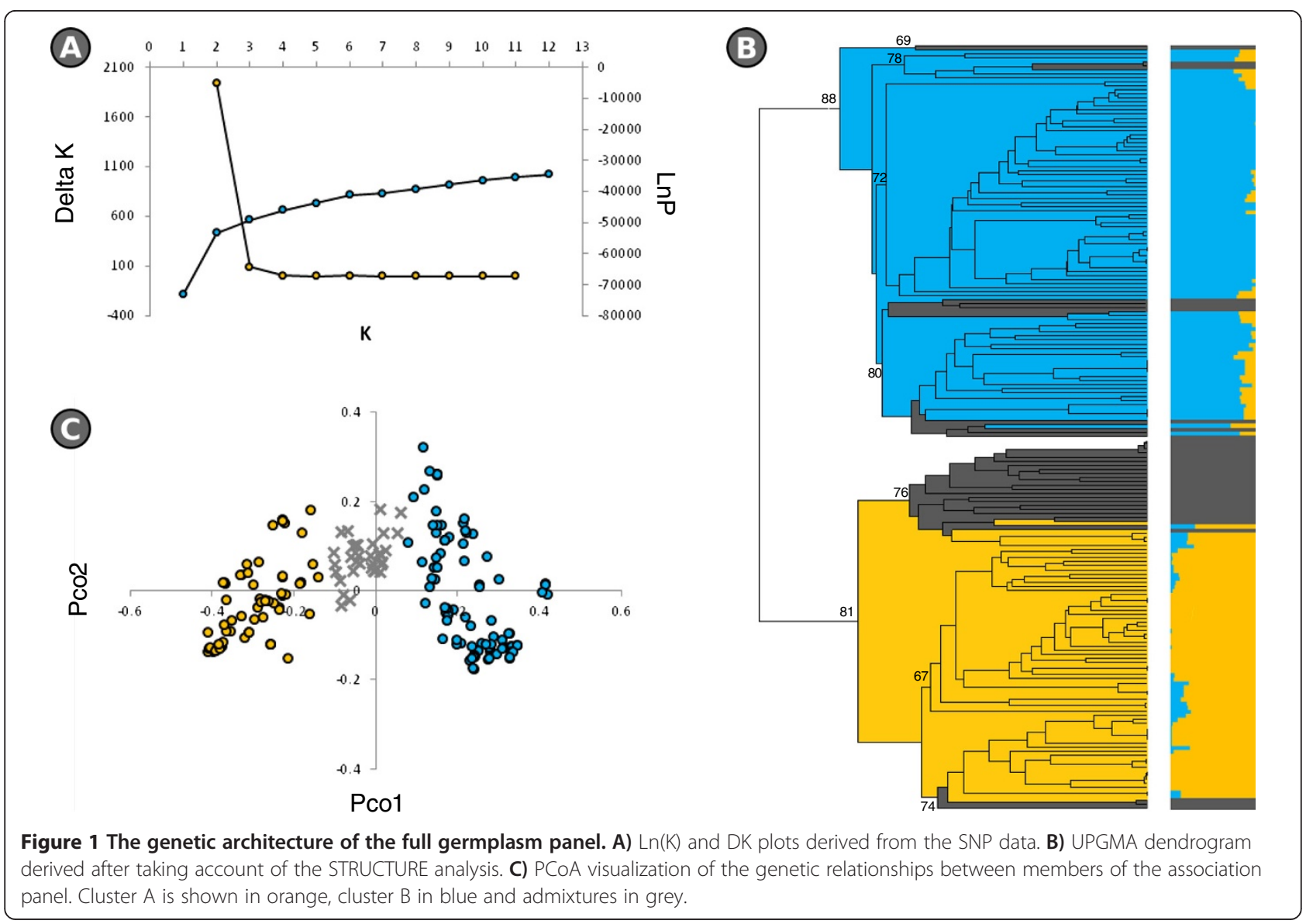




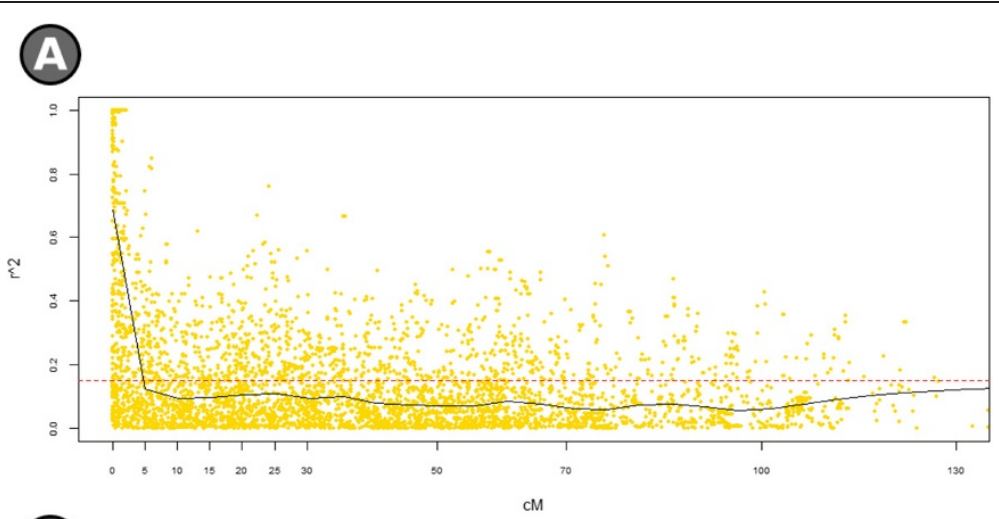

(B)

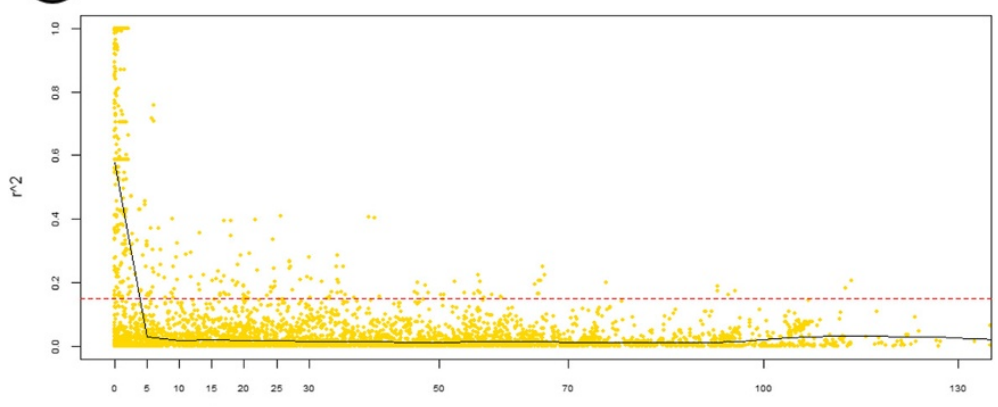

$\mathrm{cM}$

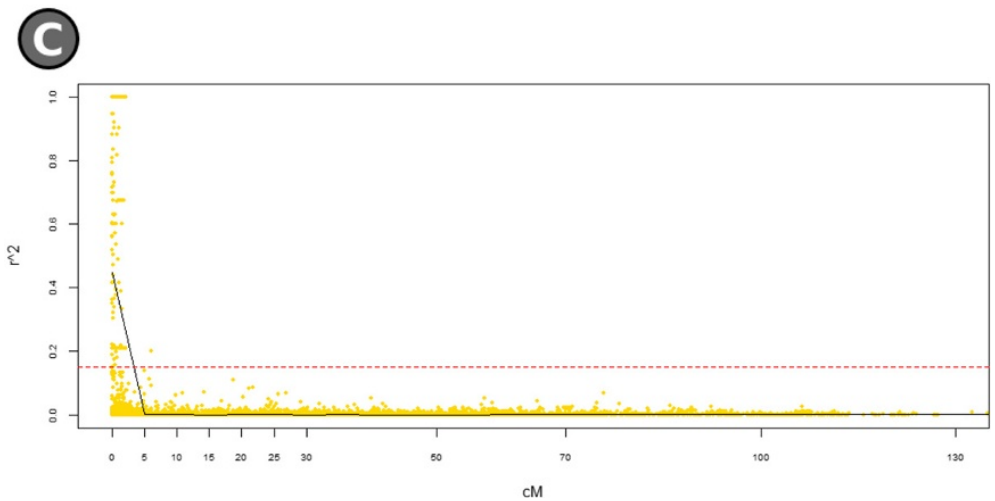

Figure 2 LD decay. The curve was fitted using a locally weighted scatterplot smooth regression with the threshold set at 0.15 . A) $r^{2}$ model, B) $r_{s}^{2}$ model, C) $r_{s v}^{2}$ model.
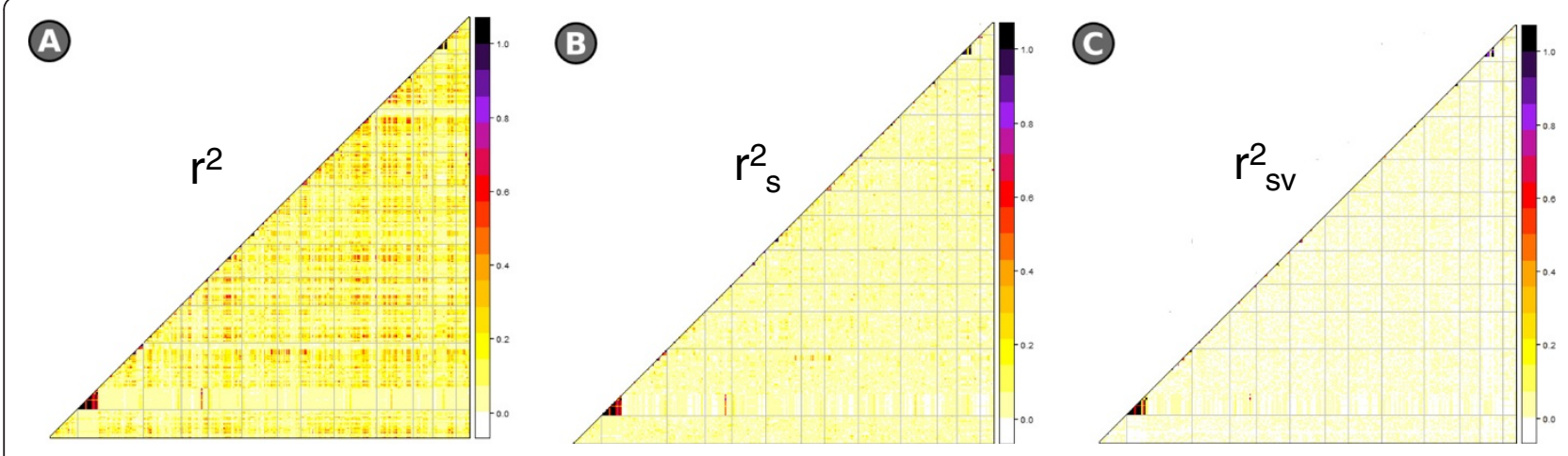

Figure 3 Heat maps indicating genome-wide variation in LD across the genome. A) $r^{2}$ model, B) $r_{s}^{2}$ model, C) $r_{s v}^{2}$ model. 
(Additional file 4: Figure S3), and also the most highly heritable. The GxE component of the variance (involving both season and location) was small, with the exception of that for corcol and fglo, the two least heritable of the traits. Broad-sense heritabilities averaged 0.71 (0.380.98), with the least heritable traits being fglo and corcol, and the most heritable pedan and $f$ col (Table 1). Some significant inter-trait correlations were observed: traits associated with the anthocyanin content of the plant (adlan, stean, ablan, calan, adlevan, ablevan and pedan) were strongly and positively correlated with one another, but only moderately correlated with corcol. The traits fglo and $f c o l$ were somewhat inter- correlated, and correlated with the anthocyanin content-related traits, but were uncorrelated with corcol. Both the correlation data and the distribution of each trait are reported in Additional file 5: Figure S4.

Associations between SNP alleles and morphology were acquired on the basis of three different models. The GLM Naive-model, which involves no correction for population structure, identified several spurious associations. This failing was improved by applying the GLM Q-model, but only the MLM K + Q-model produced a distribution of p-values comparable to the theoretical one (Figure 4). Thus the latter model was pursued. Following q-value correction, 56 significant genotype/ phenotype associations were detected. Regions carrying the presumed genes/QTL were identified on nine of the 12 chromosomes (none were detected on chromosomes E04, E09 or E12) (Table 2), and involved eight of the ten traits (no associations involved either ablan or corcol). The number of associations per trait ranged from four (calan and fglo) to 11 (stean), and the total number of SNP loci involved was 20; these loci had a mean MAF of $33.4 \%$. The PVE per association laid between $5 \%$ and $24 \%$ (mean 10\%). In order to match the associations with previously identified QTL, loci linked to one another by $<6.8 \mathrm{cM}$ were considered as a unit, and their genomic location was obtained from the Barchi et al. [10] map. Overall, 12 association groups, comprising 1-4 SNP loci, were defined in this way (Figure 5). The most prominent clustering of traits occurred on chromosome E10, which also proved to harbor the most genes/QTL underlying variation in anthocyanin content and fruit color. The E10.2 group (four SNPs) harbored genetic factors for adlan, stean, calan, adlevean, ablevean, pedan and fcol while E10.3 (three SNPs) included genetic factors for stean, ablevean, adlevean, pedan, fcol and fglo. One of the two other large clusters was on chromosome E02 (one SNP), which was influential for adlan, stean, calan and adlvean, and the other was on E05 (one SNP), with genes/QTL determining stean, adlvean, pedan and $f_{c o l}$ (Figure 5).

Detailed information regarding the individual genotype/phenotype associations is given in Table 2. The SNP locus most significantly associated with adlan was 24985_PstI_L311 (group 06.1), with a MAF of 33.5\% and a PVE of 22\%; for stean, calan, adlvean, ablvean, pedan and fcol 35442_PstI_L404 (group 10.2), with a MAF of $48.7 \%$ and a PVE of 14-24\%. For fglo, three highly significantly associated SNPs were detected, namely 3382_PstI_L285, 19601_PstI_L364 and 33571_PstI_L387; these had a MAF of $30 \%$ and each had a PVE of $10 \%$.

\section{Synteny with tomato and the identification of potential candidate genes}

The regions of chromosomes E02, E05 and E10 harboring genetic factors underlying anthocyanin content were aligned with the tomato genome sequence. E02 and T02 are known to be syntenic, while part of E05 is syntenic with the lower section of T05 and the rest with the lower section of T12; E10 corresponds to the upper section of T05 and the lower one of T10 [42,43]. Genes in tomato encoding flavonone 3-hydroxylase and dihydroflavonol 4-reductase are present on T02 in a region homologous with group E02.1, which harbors genes/

Table 1 Codes used to identify the various traits along with mean values, standard deviations (SD), coefficients of variation (CV) and broad-sense heritabilities

\begin{tabular}{|c|c|c|c|c|c|}
\hline Trait & Code & Average & SD & CV & Heritability \\
\hline Adaxial leaf lamina anthocyanin (scale 0-5) & adlan & 1.37 & 1.49 & 1.09 & 0.67 \\
\hline Stem anthocyanin (scale 0-5) & stean & 2.80 & 1.83 & 0.65 & 0.81 \\
\hline Abaxial leaf lamina anthocyanin (scale 0-5) & ablan & 1.08 & 1.08 & 1.00 & 0.55 \\
\hline Calyx anthocyanin (scale 0-5) & calan & 2.74 & 1.75 & 0.64 & 0.87 \\
\hline Corolla color (scale 0-3) & corcol & 1.49 & 0.51 & 0.34 & 0.42 \\
\hline Adaxial leaf venation anthocyanin (scale $0-5$ ) & adlvean & 2.27 & 1.53 & 0.67 & 0.75 \\
\hline Abaxial leaf venation anthocyanin (scale $0-5$ ) & ablvean & 2.26 & 1.78 & 0.78 & 0.76 \\
\hline Fruit peduncle anthocyanin (scale $0-5$ ) & pedan & 2.20 & 2.13 & 0.97 & 0.95 \\
\hline Fruit color $\left(L^{*} a^{*} b^{*}\right.$ coordinates distance from 0$)$ & fcol & 74.57 & 15.60 & 0.21 & 0.98 \\
\hline Fruit glossiness (scale $0-3$ ) & fglo & 2.37 & 0.73 & 0.31 & 0.38 \\
\hline
\end{tabular}




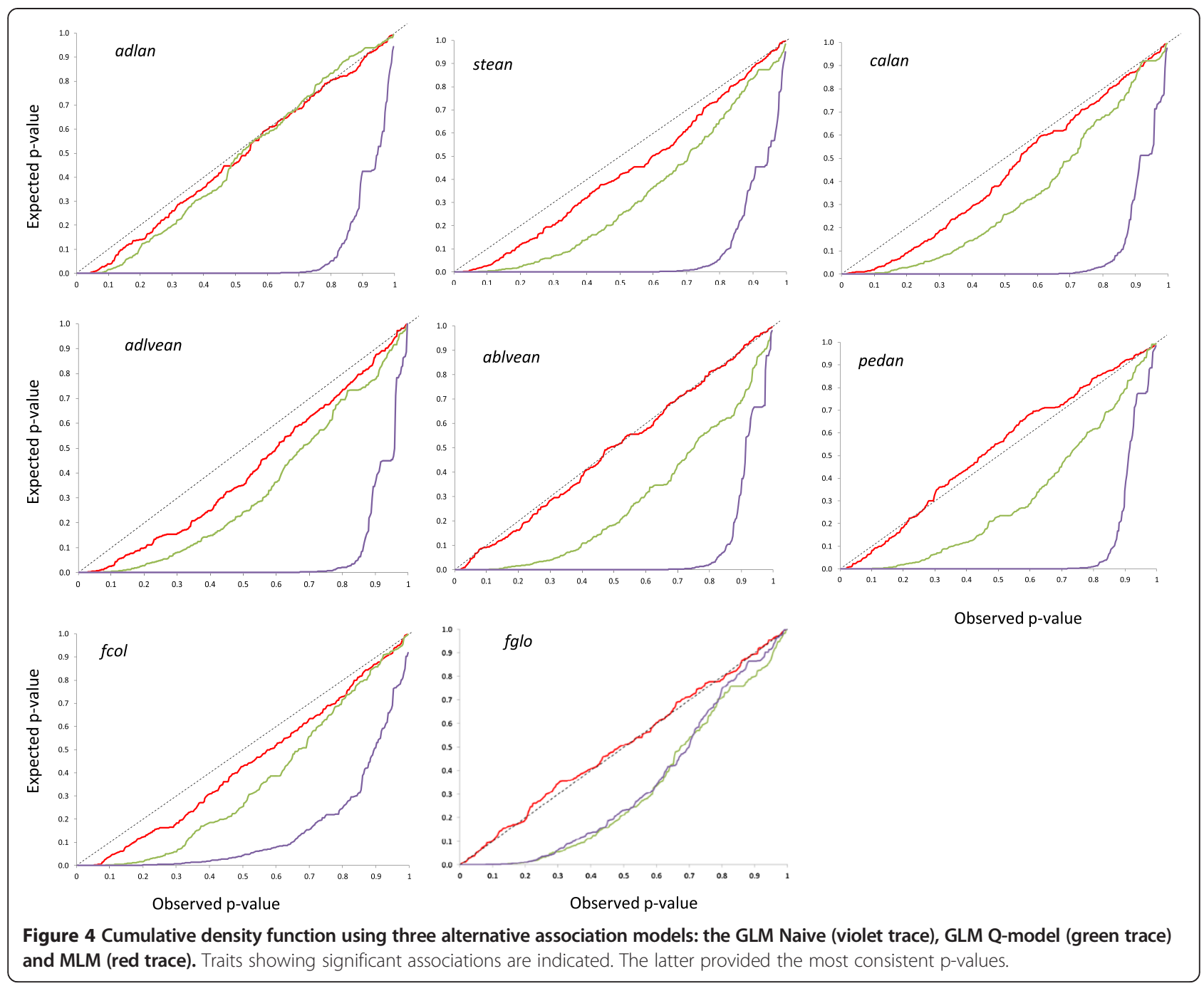

QTL for adlan, stean, calan and adlvean (Figure 6). The location of the E05.1 group (stean, adlvean, pedan and fcol) corresponds to a segment of T12 in which a gene encoding the anthocyanin synthesis-associated enzyme UDP glucose anthocyanidin 5-0 glucosyltransferase is located (Figure 6). The tomato gene encoding UDP glucose anthocyanidin 3-0 glucosyltransferase and the two MYB transcription factors Ant1 and An2 are present on $\mathrm{T} 10$, in a region syntenic to groups E10.2 and E10.3; genes/QTL in these groups had a strong influence over the pigmentation of both the vegetative parts of the plant and the fruit.

\section{Discussion}

\section{Genetic variation and population structure}

The 191 members of the association panel were deliberately selected to represent the full range of phenotypic diversity in eggplant. The panel was genotyped with a subset of 384 of the $>10,000$ SNPs identified by sequencing RAD tags generated from the genomic DNA of $67 / 3$ and 305E40, the parents of an established $F_{2}$ mapping population [44]. Most of the SNPs included in the genotyping chip were unambiguously scorable and informative, producing average MAF and PIC values of 0.30 and 0.41 , respectively. A small number of SNPs had to be discarded for reasons of poor scoring quality or low informativeness. Particularly low PIC values were obtained in the distal region of the chromosome E02 (Additional file 2: Figure $\mathrm{S1B}$ ); this chromosomal region is the site of the locus Rfo-sa1, which confers resistance against the soil-borne fungus Fusarium oxysporum f. sp. melongenae which was introgressed in the parental line 305E40 from Solanum aethiopicum gr. gilo [45,46]. Therefore, 305E40 carries some rather low frequency alleles which show a rather low frequency among the accession under study. The information provided by these polymorphisms are of 
Table 2 Significant genotypic associations with anthocyanin content- and fruit color-related traits

\begin{tabular}{|c|c|c|c|c|c|c|c|c|}
\hline Trait & Marker & Chrom. & Position (cM) & Association group & p-value & q-value & PVE & MAF \\
\hline \multirow[t]{6}{*}{ adlan } & 10532_Pstl_L317 & E01 & 28.48 & E01.1 & $5.04 \mathrm{E}-04$ & $1.19 \mathrm{E}-02$ & $8 \%$ & $24.6 \%$ \\
\hline & 21901_Pstl_L329 & E02 & 58.27 & E02.1 & $2.34 \mathrm{E}-03$ & 4.80E-02 & $6 \%$ & $19.9 \%$ \\
\hline & 24985_Pstl_L311 & E06 & 151.80 & E06.1 & $3.76 \mathrm{E}-11$ & $2.32 \mathrm{E}-09$ & $22 \%$ & $33.5 \%$ \\
\hline & 35442_Pstl_L404 & E10 & 69.13 & E10.2 & $2.04 \mathrm{E}-05$ & $5.24 \mathrm{E}-04$ & $11 \%$ & $48.7 \%$ \\
\hline & 15158_Pstl_L379 & E10 & 69.39 & E10.2 & $4.08 \mathrm{E}-07$ & $1.79 \mathrm{E}-05$ & $13 \%$ & $43.5 \%$ \\
\hline & 36033_Pstl_L358 & E11 & 68.04 & E11.1 & $1.69 \mathrm{E}-05$ & 4.74E-04 & $11 \%$ & $42.4 \%$ \\
\hline \multirow[t]{11}{*}{ stean } & 27031_Pstl_L365 & E01 & 110.78 & E01.2 & $3.25 \mathrm{E}-04$ & 1.77E-02 & $7 \%$ & $31.4 \%$ \\
\hline & 21901_Pstl_L329 & E02 & 58.27 & E02.1 & $7.73 \mathrm{E}-04$ & $2.85 \mathrm{E}-02$ & $7 \%$ & $19.9 \%$ \\
\hline & 12391_Pstl_L355 & E05 & 94.93 & E05.1 & $1.05 \mathrm{E}-03$ & $2.85 \mathrm{E}-02$ & $7 \%$ & $46.6 \%$ \\
\hline & 9226_Pstl_L398 & E08 & 1.80 & E08.1 & $1.47 \mathrm{E}-03$ & $3.63 \mathrm{E}-02$ & $5 \%$ & $19.4 \%$ \\
\hline & 35442_Pstl_L404 & E10 & 69.13 & E10.2 & 5.51E-09 & $1.50 \mathrm{E}-06$ & $18 \%$ & $48.7 \%$ \\
\hline & 15158_Pstl_L379 & E10 & 69.39 & E10.2 & $2.89 \mathrm{E}-05$ & $3.92 \mathrm{E}-03$ & $9 \%$ & $43.5 \%$ \\
\hline & 19126_Pstl_L349 & E10 & 69.39 & E10.2 & $2.08 \mathrm{E}-04$ & $1.41 \mathrm{E}-02$ & $7 \%$ & $5.7 \%$ \\
\hline & 31471_Pstl_L271 & E10 & 70.39 & E10.2 & $1.91 \mathrm{E}-03$ & $3.99 \mathrm{E}-02$ & $6 \%$ & $30.4 \%$ \\
\hline & 3382_Pstl_L285 & E10 & 128.30 & E10.3 & $9.56 \mathrm{E}-04$ & $2.85 \mathrm{E}-02$ & $6 \%$ & $29.8 \%$ \\
\hline & 19601_Pstl_L364 & E10 & 128.34 & E10.3 & $9.56 \mathrm{E}-04$ & $2.85 \mathrm{E}-02$ & $6 \%$ & $29.8 \%$ \\
\hline & 33571_Pstl_L387 & E10 & 128.55 & E10.3 & $9.56 \mathrm{E}-04$ & $2.85 \mathrm{E}-02$ & $6 \%$ & $29.8 \%$ \\
\hline \multirow[t]{4}{*}{ calan } & 21901_Pstl_L329 & E02 & 58.27 & E02.1 & 2.87E-05 & $2.71 \mathrm{E}-03$ & $11 \%$ & $19.9 \%$ \\
\hline & 31763_Pstl_L370 & E10 & 6.25 & E10.1 & 3.37E-04 & $2.39 \mathrm{E}-02$ & $8 \%$ & $43.5 \%$ \\
\hline & 35442_Pstl_L404 & E10 & 69.13 & E10.2 & $5.96 \mathrm{E}-12$ & 1.69E-09 & $24 \%$ & $48.7 \%$ \\
\hline & 15158_Pstl_L379 & E10 & 69.39 & E10.2 & $5.12 \mathrm{E}-08$ & $7.24 \mathrm{E}-06$ & $15 \%$ & $43.5 \%$ \\
\hline \multirow[t]{9}{*}{ adlvean } & 21901_Pst|_L329 & E02 & 58.27 & E02.1 & $3.74 \mathrm{E}-04$ & $1.48 \mathrm{E}-02$ & $8 \%$ & $19.9 \%$ \\
\hline & 25734_Pstl_L387 & E05 & 87.34 & E05.1 & $1.51 \mathrm{E}-03$ & $3.26 \mathrm{E}-02$ & $7 \%$ & $39.3 \%$ \\
\hline & 35442_Pstl_L404 & E10 & 69.13 & E10.2 & $1.22 \mathrm{E}-09$ & $2.91 \mathrm{E}-07$ & $20 \%$ & $48.7 \%$ \\
\hline & 15158_Pstl_L379 & E10 & 69.39 & E10.2 & $2.41 \mathrm{E}-05$ & $2.87 \mathrm{E}-03$ & $9 \%$ & $43.5 \%$ \\
\hline & 19126_Pstl_L349 & E10 & 69.39 & E10.2 & $1.36 \mathrm{E}-03$ & $3.23 \mathrm{E}-02$ & $5 \%$ & $5.7 \%$ \\
\hline & 3382_Pstl_L285 & E10 & 128.30 & E10.3 & $1.68 \mathrm{E}-04$ & 7.99E-03 & $7 \%$ & $29.8 \%$ \\
\hline & 19601_Pstl_L364 & E10 & 128.34 & E10.3 & $1.68 \mathrm{E}-04$ & 7.99E-03 & $7 \%$ & $29.8 \%$ \\
\hline & 33571_Pst|_L387 & E10 & 128.55 & E10.3 & $1.68 \mathrm{E}-04$ & 7.99E-03 & $7 \%$ & $29.8 \%$ \\
\hline & 36033_Pstl_L358 & E11 & 68.04 & E11.1 & 7.80E-04 & $2.10 \mathrm{E}-02$ & $7 \%$ & $42.4 \%$ \\
\hline \multirow[t]{6}{*}{ ablvean } & 35442_Pstl_L404 & E10 & 69.13 & E10.2 & $8.16 \mathrm{E}-07$ & $1.35 \mathrm{E}-04$ & $14 \%$ & $48.7 \%$ \\
\hline & 15158_Pstl_L379 & E10 & 69.39 & E10.2 & $4.21 \mathrm{E}-07$ & $1.35 \mathrm{E}-04$ & $13 \%$ & $43.5 \%$ \\
\hline & 31471_Pst|_L271 & E10 & 70.39 & E10.2 & 7.03E-04 & $3.87 \mathrm{E}-02$ & $7 \%$ & $30.4 \%$ \\
\hline & 3382_Pstl_L285 & E10 & 128.30 & E10.3 & $7.28 \mathrm{E}-06$ & $4.81 \mathrm{E}-04$ & $10 \%$ & $29.8 \%$ \\
\hline & 19601_Pst|_L364 & E10 & 128.34 & E10.3 & $7.28 \mathrm{E}-06$ & $4.81 \mathrm{E}-04$ & $10 \%$ & $29.8 \%$ \\
\hline & 33571_Pst|_L387 & E10 & 128.55 & E10.3 & $7.28 \mathrm{E}-06$ & 4.81E-04 & $10 \%$ & $29.8 \%$ \\
\hline \multirow[t]{6}{*}{ pedan } & 25734_Pstl_L387 & E05 & 87.34 & E05.1 & $3.80 \mathrm{E}-06$ & $4.28 \mathrm{E}-04$ & $12 \%$ & $39.3 \%$ \\
\hline & 35442_Pstl_L404 & E10 & 69.13 & E10.2 & $2.05 \mathrm{E}-10$ & $6.94 \mathrm{E}-08$ & $20 \%$ & $48.7 \%$ \\
\hline & 15158_Pstl_L379 & E10 & 69.39 & E10.2 & 1.39E-09 & $2.35 \mathrm{E}-07$ & $17 \%$ & $43.5 \%$ \\
\hline & 3382_Pstl_L285 & E10 & 128.30 & E10.3 & $1.90 \mathrm{E}-04$ & $1.07 \mathrm{E}-02$ & $7 \%$ & $29.8 \%$ \\
\hline & 19601_Pstl_L364 & E10 & 128.34 & E10.3 & $1.90 \mathrm{E}-04$ & $1.07 \mathrm{E}-02$ & $7 \%$ & $29.8 \%$ \\
\hline & 33571_Pstl_L387 & E10 & 128.55 & E10.3 & 1.90E-04 & $1.07 \mathrm{E}-02$ & $7 \%$ & $29.8 \%$ \\
\hline \multirow[t]{2}{*}{ fcol } & 27031_Pstl_L365 & E01 & 110.78 & E01.2 & 4.66E-04 & $9.83 \mathrm{E}-03$ & $7 \%$ & $31.4 \%$ \\
\hline & 25776_Pstl_L386 & E05 & 100.27 & E05.1 & 1.07E-04 & 4.53E-03 & $11 \%$ & $20.4 \%$ \\
\hline
\end{tabular}


Table 2 Significant genotypic associations with anthocyanin content- and fruit color-related traits (Continued)

\begin{tabular}{|c|c|c|c|c|c|c|c|c|}
\hline & 34571_Pstl_L286 & E07 & 15.66 & E07.1 & 2.60E-04 & $6.09 \mathrm{E}-03$ & $6 \%$ & $46.6 \%$ \\
\hline & 19381_Pstl_L396 & E10 & 64.21 & E10.2 & $8.81 \mathrm{E}-05$ & 4.53E-03 & $10 \%$ & $49.2 \%$ \\
\hline & 35442_Pstl_L404 & E10 & 69.13 & E10.2 & $1.22 \mathrm{E}-08$ & $2.58 \mathrm{E}-06$ & $22 \%$ & $48.7 \%$ \\
\hline & 19126_Pstl_L349 & E10 & 69.39 & E10.2 & $2.15 \mathrm{E}-04$ & $5.67 \mathrm{E}-03$ & $10 \%$ & $5.7 \%$ \\
\hline & 3382_Pstl_L285 & E10 & 128.30 & E10.3 & $1.51 \mathrm{E}-04$ & $4.53 \mathrm{E}-03$ & $6 \%$ & $29.8 \%$ \\
\hline & 19601_Pstl_L364 & E10 & 128.34 & E10.3 & $1.51 \mathrm{E}-04$ & 4.53E-03 & $6 \%$ & $29.8 \%$ \\
\hline & 33571_Pstl_L387 & E10 & 128.55 & E10.3 & $1.51 \mathrm{E}-04$ & 4.53E-03 & $6 \%$ & $29.8 \%$ \\
\hline & 36033_Pstl_L358 & E11 & 68.04 & E11.1 & $6.92 \mathrm{E}-06$ & 7.30E-04 & $17 \%$ & $42.4 \%$ \\
\hline fglo & 3687_Pstl_L304 & E03 & 104.00 & E03.1 & 4.87E-04 & $3.88 \mathrm{E}-02$ & $6 \%$ & $23 \%$ \\
\hline & 3382_Pstl_L285 & E10 & 128.30 & E10.3 & 1.07E-05 & $1.14 \mathrm{E}-03$ & $10 \%$ & $30 \%$ \\
\hline & 19601_Pstl_L364 & E10 & 128.34 & E10.3 & 1.07E-05 & $1.14 \mathrm{E}-03$ & $10 \%$ & $30 \%$ \\
\hline & 33571_Pstl_L387 & E10 & 128.55 & E10.3 & 1.07E-05 & 1.14E-03 & $10 \%$ & $30 \%$ \\
\hline
\end{tabular}

The associated SNPs' ID, genomic location, relevant association group, the significance of the association (both p- and q-values), PVE (phenotypic variability explained) and MAF (minimum allele frequency) are shown.

interest only in the artificial progeny in which they are well represented while may result of scarce usefulness in a germplasm panel.

The population structure of the panel (Figure 1) comprised two rather distinct sub-populations, which broadly matched the accessions' provenance. The species is thought to have been domesticated in Asia [47-49] and introduced into the Mediterranean basin by the Arabs in the $7^{\text {th }}$ to $8^{\text {th }}$ century CE [50]. The distinctness of the two gene-pools reflects a history of independent selection and adaptation to different environments and consumer preferences. When the PCO analysis was applied to just the "Occidental" entries no evidence of correlation between provenance and genetic relatedness was found, while a clustering related to the three morphological groups we previously described (i.e. group 1 -long, light and curved fruits-, group 2 -oblong shaped, medium weighted fruits- and group 3 -round an heavy fruits), was detected (Additional file 3: Figure S2B) [17]. Possibly, different uses of different types of fruits may have generated separate groups of varieties cultivated in different areas, with a different history of selection responsible of the observed genetic differentiation. The picture was rather different for the "Oriental" gene pool (Additional file 3: Figure S2A); the Asian material did form two recognizable clusters (Additional file 3: Figure S2A), with most of the Indian, SE Asian and Indonesian materials forming one group and the Chinese ones the other. This behavior replicated the outcome of a previous diversity study based on SSR markers [17], thereby further supporting the hypothesis that eggplant was domesticated independently in the Indian subcontinent and in China $[47,49]$.

\section{LD in eggplant}

In order to account for population structure, two different corrections to the $r^{2}$ measure were attempted, as proposed by Mangin et al. [25]. The estimate of LD derived without these corrections was unreliable, as it included apparent associations over long intra-chromosomal distances (Figure 2), and even between loci mapping to two different chromosomes (Figure 3). Applying the $r_{s}^{2}$ model reduced the extent of these clearly artefactual associations, but a more stringent method was still needed to correct for bias due to genetic relatedness. This was provided by the $r_{\mathrm{sv}}^{2}$ model, which achieved a 30 fold reduction in associations between unlinked markers, leaving high LD values only between pairs of genetically linked SNP loci. The end estimate for the extension of LD was $3.4 \mathrm{cM}$, which matches reasonably well with the level reported for eggplant by Ge et al. [16], and also with those documented in other self-pollinating species such as the near-relative tomato (6-8 cM; [51]), Arabidopsis thaliana (10 kb; [52]), barley (3.5 cM; [26]) and wheat (1-5 cM; [27]). LD was not uniformly distributed along the genome (Figure 3), a phenomenon which has also been noted elsewhere $[27,51,53,54]$. Its non-uniformity is thought to reflect the irregular distribution of recombination along the chromosome, but can also be influenced by positive selection [55]. Furthermore, the high level of LD and extended haplotype blocks in our material may be due to the high level of homozygosity which can hardly generate recombinations as well as the genetic bottleneck due to selection which drastically reduced the low frequent haplotypes and extended the association between markers. Such a level of LD is ideal for the GWA method, as it allows for an efficient coverage of the genome based on a relatively moderate number of markers, while still encouraging a high level of genetic diversity.

\section{GWA mapping of genetic factors underlying anthocyanin pigmentation and fruit color}

QTL discovery in eggplant has to date been achieved using linkage mapping in bi-parental inter and intraspecific populations $[6,7,10,11,56]$. A first attempt to 


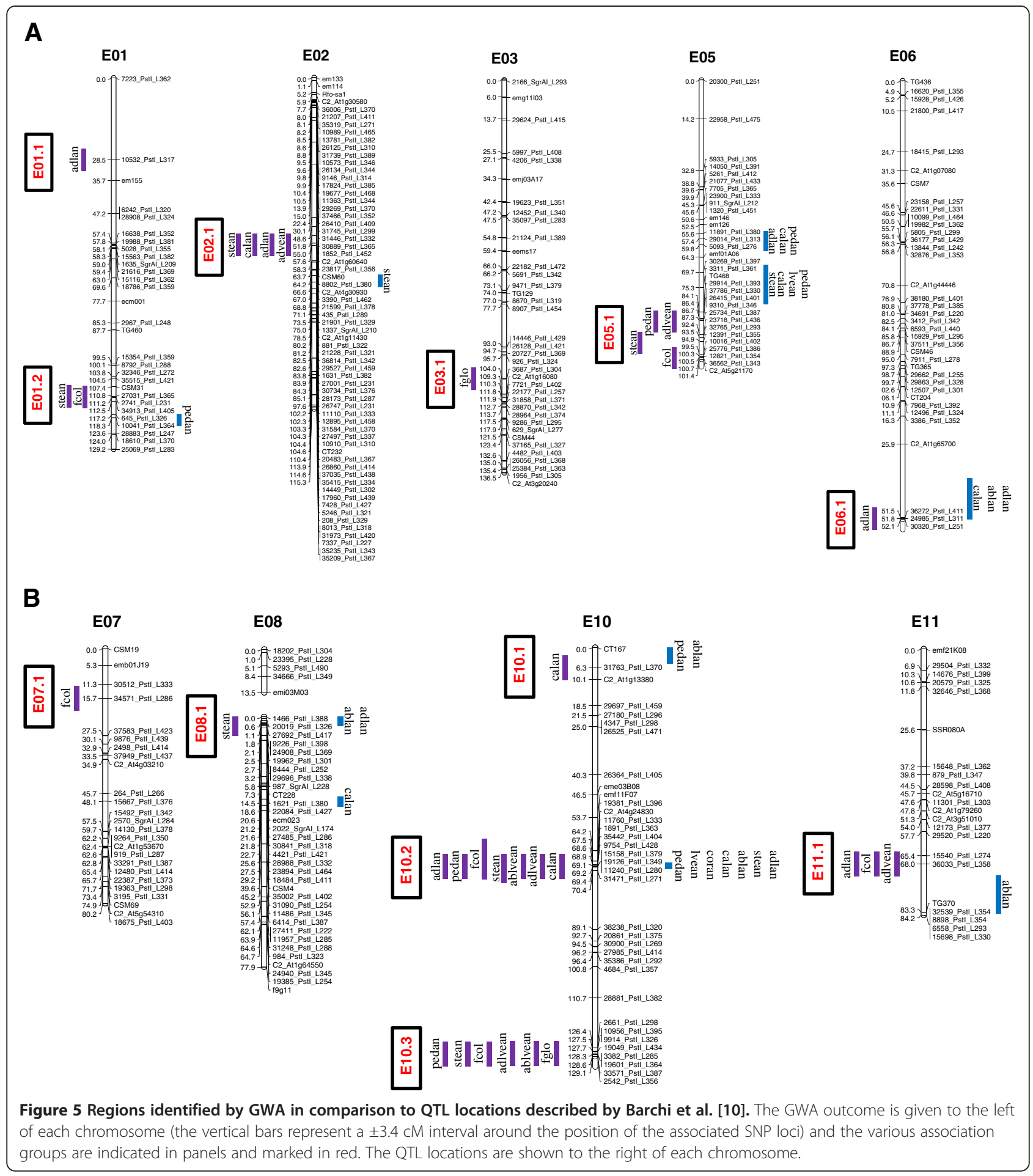

apply GWA has been published recently [16], in which 49 marker associations related to eight traits were reported. Some potentially fatal weaknesses in the analysis can, however, be identified. Firstly, the issue of a MAF threshold was not addressed, so it is not clear whether loci associated with a low MAF were discarded or included; the effect of their inclusion would be to generate false associations caused by the co-incidence of variation for a trait and a statistically under-represented allele. Secondly, the GLM model was used to estimate the significance of locus/trait associations, but this method has been shown to be incapable of adequately correcting for population structure [15,57], unlike the MLM model used in the present study. Thirdly, no evidence of 


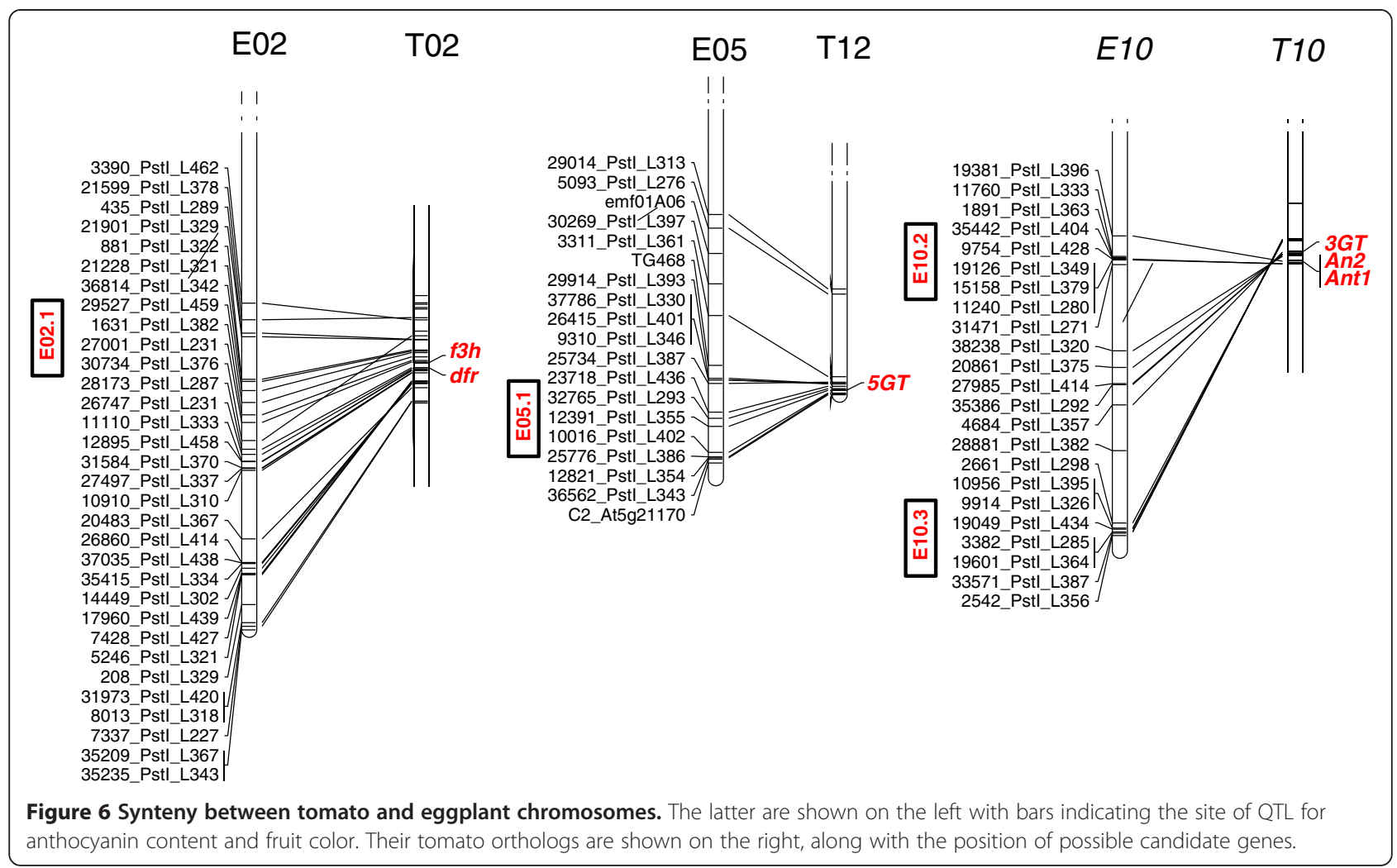

correcting for spurious associations (such as a q-q plot or a cumulative density function) was provided. Fourthly, a threshold false positive rate (p-value) of 0.01 was adopted as a threshold to validate the associations, instead of using a corrected threshold (e.g. the Bonferroni correction), or one for the false discovery rate.

The genetic basis of anthocyanin synthesis and accumulation has been widely explored in the Solanaceae [58-64]. In eggplant, this has long been thought to be rather complex $[65,66]$, involving at least three major and five minor loci, with the added complication of epistatic interactions and/or pleiotropic effects. The GWA procedure generated 56 associations between SNP loci and either anthocyanin content- or fruit color-related traits. According to Collard et al. [67], a QTL associated with a PVE of at least $10 \%$ should be considered as a "major" locus. There was a lack of any significant association involving corcol and ablan, but at least one "major" QTL was putatively identified for each of the other eight traits. The SNP loci associated with one (or more) traits were clustered into 12 groups, scattered over nine chromosomes. The extent of some of the inter-trait correlations suggests that what appeared to be a cluster of QTL is more likely a single pleiotropic locus, although the presence of a set of linked QTL cannot be definitively ruled out. Broad-sense heritabilities were generally $>0.5$ (the exceptions were fglo (0.38) and corcol (0.42)) with a limited genotype by environment effect, which confirms the proposition that the influence of the growing environment on anthocyanin pigmentation is quite limited $[10,68]$.

The genomic location of eight of the 12 association groups overlapped that of a known QTL, showing how effective GWA can be in identifying the genetic basis of quantitative traits. QTL identified via linkage analysis of bi-parental populations are generally considered to be experiment-specific, unless validated [69] and have often proven to be genetic background specific as well. Of the 20 SNP loci involved in the genotype/phenotype associations discovered here, six mapped to four genomic regions where no QTL related to anthocyanin content or fruit color has yet been reported (association groups E01.1, E03.1, E07.1 and E10.3; Figure 5, Table 3). Some of these markers could only have been identified thanks to the extent of the genetic variability which the GWA approach makes accessible; following a validation exercise, they may well prove to provide viable indirect selection tools in a practical breeding programme. The GWA study of Ge et al. [16] has located two marker/fcol associations, one on chromosome E01 and the other on E05, in correspondence to the association groups E01.2 and E05.1 carrying QTLs for the same trait.

\section{Synteny and possible orthologs in other Solanaceae species}

To date most of the effort invested in the genetic analysis of anthocyanin pigmentation in the Solanaceae has 
Table 3 Genotype/phenotype associations and known QTL location

\begin{tabular}{|c|c|c|c|c|}
\hline \multirow[b]{2}{*}{ Chromosome } & \multicolumn{2}{|c|}{ GWA mapping } & \multicolumn{2}{|c|}{ Family-based QTL mapping } \\
\hline & Association Group & Trait & $\overline{\mathrm{QTL}}$ & Reference \\
\hline \multirow[t]{4}{*}{ E01 } & E01.1 & adlan & - & - \\
\hline & E01.2 & stean & - & - \\
\hline & & fcol & fail.1 & Doganlar et al. [6] \\
\hline & & & fap & Ge et al. [16] \\
\hline \multirow[t]{4}{*}{ E02 } & E02.1 & adlan & Ila2.2 & Doganlar et al. [6] \\
\hline & & stean & steanE02.MT & Barchi et al. [10] \\
\hline & & calan & - & - \\
\hline & & adlvean & - & - \\
\hline E03 & E03.1 & fglo & - & - \\
\hline \multirow[t]{4}{*}{ E05 } & E05.1 & stean & steanE05.ML; steanE05.MT & Barchi et al. [10] \\
\hline & & adlvean & IveanE05.ML; IveanE05. MT & Barchi et al. [10] \\
\hline & & pedan & pedanE05.ML; pedanE05.MT & Barchi et al. [10] \\
\hline & & fcol & fap & Ge et al. [16] \\
\hline \multirow[t]{2}{*}{ E06 } & E06.1 & adlan & ablanE06.ML & Barchi et al. [10] \\
\hline & & & \|la6.1 & Doganlar et al. [6] \\
\hline E07 & E07.1 & fcol & - & - \\
\hline E08 & E08.1 & stean & - & - \\
\hline \multirow[t]{16}{*}{ E10 } & E10.1 & calan & - & - \\
\hline & E10.2 & adlan & ablanE10a.ML; ablanE10a.MT & Barchi et al. [10] \\
\hline & & & Ila10.1 & Doganlar et al. [6] \\
\hline & & stean & steanE10.ML; steanE10.ML & Barchi et al. [10] \\
\hline & & & sa10.1 & Doganlar et al. [6] \\
\hline & & calan & calanE10.ML; calanE10.MT & Barchi et al. [10] \\
\hline & & adlvean & IveanE10.ML; IveanE10.MT & Barchi et al. [10] \\
\hline & & ablvean & IveanE10.ML; IveanE10.MT & Barchi et al. [10] \\
\hline & & pedan & - & - \\
\hline & & fcol & fap10.1; fai10.1; fc10.1 & Doganlar et al. [6] \\
\hline & E10.3 & stean & - & - \\
\hline & & adlvean & - & - \\
\hline & & ablvean & - & - \\
\hline & & pedan & - & - \\
\hline & & fcol & - & - \\
\hline & & fglo & - & - \\
\hline E11 & E11.1 & adlan & ablanE11.ML & Barchi et al. [10] \\
\hline E11 & & adlvean & - & - \\
\hline E11 & & $f \mathrm{col}$ & - & - \\
\hline
\end{tabular}

The four locations where no QTL related to anthocyanin content or fruit color have been located are shown in bold.

been focused on potato, sweet pepper and tomato. In the latter crop, 13 genes (some encoding enzymes and transcription factors) involved in anthocyanin synthesis have been described [62]. The detailed understanding of this pathway, along with the well-established syntenic relationships between the tomato and eggplant chromosomes $[10,42,70]$, means that it is reasonable to search for candidate genes in eggplant by inspecting the gene content of the syntenic tomato sequence. Synteny was observed between E02.1 (harboring marker/trait associations for stean, adlan, calan and adlvean) and a portion of tomato chromosome T02, where two genes encoding enzymes (flavonone 3-hydroxilase and dihydroflavonol 4-reductase) involved in the anthocyanin production 
pathway reside. One of these has been identified as the gene underlying the aw (anthocyanin without) QTL, in the presence of which there is a complete absence of anthocyanin throughout plant development [71]. The same gene is responsible for the potato $R$ QTL [72], which produces red pelargonidin-based anthocyanin pigments. E05.1 (harboring marker/trait associations for adlvean, pedan, stean and $f(o l)$ lies in a region syntenic to a portion of T12 which harbors 5GT, a gene involved in the storage of betanidin (a fruit and flower pigment) in the vacuole [73]. E10.2 and E10.3 (harboring marker/ trait associations for ablvean, adlan, adlvean, calan, fcol, fglo, pedan and stean) share synteny with a portion of T10 which carries several genes related to the anthocyanin production pathway, $3 G T$ and the two MYB transcription factors ANT1 and AN2 (a and b loci) [62]. ANT1 regulates the genes encoding chalcone synthase and dihydroflavonol 4-reductase, key enzymes involved in the synthesis of anthocyanin compounds [74]. ANT1 is considered to be the prime candidate for the $a g$ (anthocyanin gainer) QTL responsible for the delayed expression of anthocyanin [70]. In potato, AN2a is the likely candidate for $Q T L I$, responsible for tissue-specific anthocyanin expression $[59,75]$ and $A N 2 \mathrm{~b}$ for $F$, a regulator of anthocyanin expression in the flower [58]. In sweet pepper, a MYB transcription factor encoded by $A$ underlies the accumulation of anthocyanin pigment in the foliage, flower and immature fruit [61].

\section{Conclusion}

The development of large-scale genotyping capacity has allowed the concept of GWA to become a viable approach for the genetic dissection of quantitative traits. Here, the technique has been applied to uncover the genomic regions harboring genes underlying anthocyanin pigmentation and fruit color traits in eggplant. The GWA mapping approach was effective in validating a number of established QTL and, thanks to the wide diversity captured by the panel of genotypes in study, was able to detect a series of novel marker/trait associations. Synteny with tomato has allowed the ready identification of candidate orthologues for the chromosome E02, E05 and E12 QTLs related to anthocyanin accumulation.

\section{Availability of supporting data}

The data sets supporting the results of this article are available in the LabArchives repository at the following web address http://dx.doi.org/10.6070/H4NG4NK5.

\section{Additional files}

Additional file 1: Table S1. List of the accessions used for the association mapping study.
Additional file 2: Figure S1. A) SNP performance. Loci with a MAF $<0.05$ were excluded from the GWA analysis. B) SNP PIC values across chromosomes. The solid line represents the average genome-wide $\mathrm{PIC}$, and the broken line the variation in PIC value across chromosome E02; note the particularly low informativeness of loci at the distal end of this chromosome.

Additional file 3: Figure S2. The genetic architecture of the components of the germplasm panel. A) PCoA of the EA accessions. Those of Chinese origin cluster to the right of the plot, separated from those of S and SE Asian origin. B) PCOA of the WA accessions cluster according to their fruit morphology: group 1 - long, light, curved fruits, group 2 - oblong fruits of intermediate weight, group 3 - round, heavy fruits as defined by Cericola et al. [17].

Additional file 4: Figure S3. PVE values. adlan = adaxial leaf lamina anthocyanin; stean = Stem anthocyanin; ablan = abaxial leaf lamina anthocyanin; calan = calyx anthocyanin; corcol = corolla color; adlvean = adaxial leaf venation anthocyanin; ablvean = abaxial leaf venation anthocyanin; pedan $=$ fruit peduncle anthocyanin; $\mathrm{fcol}=$ fruit color; fglo = fruit glossiness. $\operatorname{Var}(\mathrm{g})$ = genotypic variance; $\operatorname{Var}(\mathrm{m})=$ genotype by location variance; $\operatorname{Var}(n)=$ genotype by year variance; $\operatorname{Var}(\mathrm{e})=$ residual variance.

Additional file 5: Figure S4. Pearson's inter-trait correlations (upper part of the matrix) and regression coefficients (lower part). The histograms included on the diagonal show the distribution of trait values (see also Table 1).

\section{Competing interests}

The authors declare that they have no competing interests.

\section{Authors' contributions}

GLR, EP and SL planned and supervised the experimental work; FC, LT, LB, NA, LP, TS and GLR performed traits evaluation over the two years and over the two experimental fields; FC and LB performed the molecular experiment; FC and EP analyzed the data; FC, EP, SL, LT and GLR drafted the manuscript; all authors read and approved the final version of the manuscript.

\section{Acknowledgments}

This research was partially supported by the Italian Ministry of Agricultural Alimentary and Forest Politics in the framework of the "ESPLORA" project. We thank Ciriaci T., Grazioli G., and Tacconi M.G. for the technical practices and data collection in the fields for eggplant production.

\section{Author details}

'Dipartimento di Scienze Agrarie, Forestali e Alimentari (DISAFA) - Plant Genetics and Breeding, University of Torino, Largo P. Braccini 2, I-10095 Grugliasco, Torino, Italy. ${ }^{2}$ Consiglio per la Ricerca e Sperimentazione in Agricoltura - CRA-ORL, Research Unit for Vegetable Crops, I-26836 Montanaso Lombardo, Lodi, Italy. ${ }^{3}$ Consiglio per la Ricerca e Sperimentazione in Agricoltura - CRA-ORA, Research Unit for Vegetable Crops, I-63030 Monsampolo del Tronto, Ascoli Piceno, Italy.

Received: 4 June 2014 Accepted: 6 October 2014

Published: 14 October 2014

\section{References}

1. FAOSTAT: http://faostat.fao.org/.

2. Rao GU, Ben Chaim A, Borovsky Y, Paran I: Mapping of yield-related QTLs in pepper in an interspecific cross of Capsicum annuum and C. frutescens. Theor App/ Genet 2003, 106(8):1457-1466.

3. Tanksley SD: The genetic, developmental, and molecular bases of fruit size and shape variation in tomato. The Plant Cell Online 2004, 16(suppl 1):S181-S189.

4. Bradshaw J, Hackett C, Pande B, Waugh R, Bryan G: QTL mapping of yield, agronomic and quality traits in tetraploid potato (Solanum tuberosum subsp. tuberosum). Theor Appl Genet 2008, 116(2):193-211.

5. Nunome T, Ishiguro K, Yoshida T, Hirai M: Mapping of fruit shape and color development traits in eggplant (Solanum melongena L.) based on RAPD and AFLP markers. Breed Sci 2001, 51(1):19-26.

6. Doganlar S, Frary A, Daunay M, Lester R, Tanksley S: A comparative genetic linkage map of eggplant (Solanum melongena) and its implications for genome evolution in the Solanaceae. Genetics 2002, 161(4):1697-1711. 
7. Frary A, Doganlar S, Daunay MC, Tanksley SD: QTL analysis of morphological traits in eggplant and implications for conservation of gene function during evolution of solanaceous species. Theor Appl Genet 2003, 107(2):359-370.

8. Miyatake K, Saito T, Negoro S, Yamaguchi H, Nunome T, Ohyama A, Fukuoka H: Development of selective markers linked to a major QTL for parthenocarpy in eggplant (Solanum melongena L.). Theor Appl Genet 2012, 124(8):1-11.

9. Lebeau A, Daunay MC, Frary A, Palloix A, Wang JF, Dintinger J, Chiroleu F, Wicker $E$, Prior $P$ : Bacterial wilt resistance in tomato, pepper, and eggplant: genetic resources respond to diverse strains in the Ralstonia solanacearum species complex. Phytopathology 2011, 101(1):154-165.

10. Barchi L, Lanteri S, Portis E, Valè G, Volante A, Pulcini L, Ciriaci T, Acciarri N, Barbierato $V$, Toppino $L$, Rotino GL: A RAD tag derived marker based eggplant linkage map and the location of QTLs determining anthocyanin pigmentation. PLoS One 2012, 7(8):e43740.

11. Portis E, Barchi L, Toppino L, Lanteri S, Acciarri N, Felicioni N, Fusari F, Barbierato V, Cericola F, Valè G, Rotino GL: QTL mapping in eggplant reveals clusters of yield-related loci and orthology with the tomato genome. PLoS One 2014, 9(2):e89499.

12. Rafalski JA: Association genetics in crop improvement. Curr Opin Plant Biol 2010, 13(2):174-180.

13. Myles S, Peiffer J, Brown PJ, Ersoz ES, Zhang Z, Costich DE, Buckler ES: Association mapping: critical considerations shift from genotyping to experimental design. The Plant Cell Online 2009, 21(8):2194-2202.

14. Rafalski A, Morgante M: Corn and humans: recombination and linkage disequilibrium in two genomes of similar size. Trends Genet 2004, 20(2):103-111.

15. Yu J, Pressoir G, Briggs WH, Vroh Bi I, Yamasaki M, Doebley JF, McMullen MD, Gaut BS, Nielsen DM, Holland JB, Kresovich S, Buckler ES: A unified mixed-model method for association mapping that accounts for multiple levels of relatedness. Nat Genet 2006, 38(2):203-208.

16. Ge HY, Liu Y, Zhang J, Han HQ, Li HZ, Shao WT, Chen HY: Simple sequence repeat-based association analysis of fruit traits in eggplant (Solanum melongena). Genet Mol Res 2013, 12:5651-5663.

17. Cericola F, Portis E, Toppino L, Barchi L, Acciarri N, Ciriaci T, Sala T, Rotino $G L$, Lanteri S: The population structure and diversity of eggplant from Asia and the Mediterranean Basin. PLoS One 2013, 8(9):e73702.

18. Barchi L, Lanteri S, Portis E, Acquadro A, Vale G, Toppino L, Rotino G: Identification of SNP and SSR markers in eggplant using RAD tag sequencing. BMC Genomics 2011, 12:304.

19. Anderson J, Churcill G, Autrique J, Tanksley S, Sorrels M: Optimizing parental selection for genetic linkage maps. Genome 1993, 36:181-186.

20. Dice LR: Measures of the amount of ecologic association between species. Ecology 1945, 26:297-302.

21. Hammer $\varnothing$, Harper DAT, Ryan PD: Past: paleontological statistics software package for education and data analysis. Palaeontologia Electronica 2001, 4:9.

22. Pritchard J, Stephens M, Donnelly P: Inference of population structure using multilocus genotype data. Genetics 2000, 155(2):945-959.

23. Evanno G, Regnaut S, Goudet J: Detecting the number of clusters of individuals using the software structure: a simulation study. $\mathrm{Mol} \mathrm{ECO}$ 2005, 14(8):2611-2620.

24. Hardy OJ, Vekemans X: Spagedi: a versatile computer program to analyse spatial genetic structure at the individual or population levels. Mol Ecol Notes 2002, 2(4):618-620.

25. Mangin B, Siberchicot A, Nicolas S, Doligez A, This P, Cierco-Ayrolles C: Novel measures of linkage disequilibrium that correct the bias due to population structure and relatedness. Heredity 2012, 108(3):285-291.

26. Comadran J, Thomas WTB, Eeuwijk FÁ, Ceccarelli S, Grando S, Stanca AM Pecchioni N, Akar T, Al-Yassin A, Benbelkacem A, Ouabbou H, Bort J, Romagosa I, Hackett CA, Russell JR: Patterns of genetic diversity and linkage disequilibrium in a highly structured Hordeum vulgare association-mapping population for the Mediterranean basin. Theor Appl Genet 2009, 119(1):175-187.

27. Breseghello F, Sorrells ME: Association analysis as a strategy for improvement of quantitative traits in plants. Crop Sci 2006, 46:1323-1330.

28. Flint-Garcia S, Thornsberry J, Buckler E: Structure of linkage disequilibrium in plants. Annu Rev Plant Biol 2003, 54:357-374.

29. ECPGR: Minimum descriptors for eggplant, Capsicum (sweet and hot pepper) and tomato. 2008

30. IBPGR: Descriptors for eggplant. Rome: International Board for Plant Genetic Resources; 1990.
31. Prohens J, Rodríguez-Burruezo A, Raigón MD, Nuez F: Total phenolic concentration and browning susceptibility in a collection of different varietal types and hybrids of eggplant: implications for breeding for higher nutritional quality and reduced browning. J Am Soc Horticultural Sci 2007, 132(5):638-646.

32. Team R: R: A Language and Environment for Statistical Computing. 2009.

33. Bradbury PJ, Zhang Z, Kroon DE, Casstevens TM, Ramdoss Y, Buckler ES: TASSEL: software for association mapping of complex traits in diverse samples. Bioinformatics 2007, 23(19):2633-2635.

34. Malosetti $M$, van der Linden CG, Vosman B, van Eeuwijk FA: A mixed-model approach to association mapping using pedigree information with an illustration of resistance to Phytophthora infestans in potato. Genetics 2007, 175(2):879-889.

35. Maccaferri M, Sanguineti MC, Mantovani P, Demontis A, Massi A, Ammar K, Kolmer JA, Czembor JH, Ezrati S, Tuberosa R: Association mapping of leaf rust response in durum wheat. Mol Breed 2010, 26(2):189-228

36. Zhou H, Steffenson BJ, Muehlbauer G, Wanyera R, Njau P, Ndeda S: Association mapping of stem rust race TTKSK resistance in US barley breeding germplasm. Theor App/ Genet 2014, 127(6):1293-1304.

37. Storey JD: A direct approach to false discovery rates. J Roy Stat Soc B 2002, 64(3):479-498

38. Storey JD, Tibshirani R: Statistical significance for genomewide studies. Proc Natl Acad Sci 2003, 100(16):9440-9445.

39. Voorrips R: MapChart: software for the graphical presentation of linkage maps and QTLs. J Hered 2002, 93(1):77-78.

40. Baird NA, Etter PD, Atwood TS, Currey MC, Shiver AL, Lewis ZA, Selker EU, Cresko WA, Johnson EA: Rapid SNP discovery and genetic mapping using sequenced RAD markers. PLoS One 2008, 3(10):e3376.

41. Li H, Durbin R: Fast and accurate short read alignment with BurrowsWheeler transform. Bioinformatics 2009, 25(14):1754-1760.

42. Wu F, Eannetta N, Xu Y, Tanksley S: A detailed synteny map of the eggplant genome based on conserved ortholog set II (COSII) markers. Theor App/ Genet 2009, 118(5):927-935.

43. Wu F, Tanksley S: Chromosomal evolution in the plant family Solanaceae. BMC Genomics 2010, 11(1):182.

44. Barchi L, Lanteri S, Portis E, Stagel A, Vale G, Toppino L, Rotino GL: Segregation distortion and linkage analysis in eggplant (Solanum melongena L.). Genome 2010, 53(10):805-815

45. Rizza F, Mennella G, Collonnier C, Shiachakr D, Kashyap V, Rajam M, Prestera M, Rotino GL: Androgenic dihaploids from somatic hybrids between Solanum melongena and S. aethiopicum group gilo as a source of resistance to Fusarium oxysporum f. sp melongenae. Plant Cell Rep 2002, 20(11):1022-1032.

46. Toppino L, Vale G, Rotino G: Inheritance of Fusarium wilt resistance introgressed from Solanum aethiopicum Gilo and Aculeatum groups into cultivated eggplant (S. melongena) and development of associated PCR-based markers. Mol Breed 2008, 22(2):237-250.

47. Meyer RS, Karol KG, Little DP, Nee MH, Litt A: Phylogeographic relationships among Asian eggplants and new perspectives on eggplant domestication. Mol Phylogenet Evol 2012, 63(3):685-701.

48. Knapp S, Vorontsova MS, Prohens J: Wild relatives of the eggplant (Solanum melongena L.: Solanaceae): new understanding of species names in a Complex Group. PLoS One 2013, 8(2):e57039.

49. Ali Z, Xu ZL, Zhang DY, He XL, Bahadur S, Yi JX: Molecular diversity analysis of eggplant (Solanum melongena) genetic resources. Genet $\mathrm{Mol}$ Res 2011, 10:1141-1155.

50. Daunay MC: Eggplant. In Handbook of crop breeding, Vegetables II: Fabaceae, Liliaceae, Umbelliferae, and Solanaceae. Edited by Prohens aFNe J. New York: Springer; 2008:163-220.

51. Robbins MD, Sim S-C, Yang W, Van Deynze A, van der Knaap E, Joobeur T, Francis DM: Mapping and linkage disequilibrium analysis with a genomewide collection of SNPs that detect polymorphism in cultivated tomato. J Exp Bot 2011, 62(6):1831-1845.

52. Kim S, Plagnol V, Hu TT, Toomajian C, Clark RM, Ossowski S, Ecker JR, Weigel D, Nordborg M: Recombination and linkage disequilibrium in Arabidopsis thaliana. Nat Genet 2007, 39(9):1151-1155.

53. Li L, Paulo M-J, Strahwald J, Lübeck J, Hofferbert H-R, Tacke E, Junghans $H_{\text {, }}$ Wunder J, Draffehn A, Eeuwijk F, Gebhardt C: Natural DNA variation at candidate loci is associated with potato chip color, tuber starch content, yield and starch yield. Theor Appl Genet 2008, 116(8):1167-1181. 
54. Ranc N, Muños S, Xu J, Le Paslier M-C, Chauveau A, Bounon R, Rolland S, Bouchet J-P, Brunel D, Causse M: Genome-wide association mapping in tomato (Solanum lycopersicum) is possible using genome admixture of Solanum lycopersicum var. cerasiforme. G3: Genes|Genomes|Genetics 2012, 2(8):853-864

55. Whitt SR, Wilson LM, Tenaillon MI, Gaut BS, Buckler ES: Genetic diversity and selection in the maize starch pathway. Proc Natl Acad Sci 2002, 99(20):12959-12962.

56. Frary A, Frary A, Daunay M-C, Huvenaars K, Mank R, Doğanlar S: QTL hotspots in eggplant (Solanum melongena) detected with a high resolution map and CIM analysis. Euphytica 2014, 197(2):211-228.

57. Yang J, Zaitlen NA, Goddard ME, Visscher PM, Price AL: Advantages and pitfalls in the application of mixed-model association methods. Nat Genet 2014, 46(2):100-106.

58. van Eck HJ, Jacobs JME, Dijk J, Stiekema WJ, Jacobsen E: Identification and mapping of three flower colour loci of potato (S. tuberosum L.) by RFLP analysis. Theor Appl Genet 1993, 86(2):295-300

59. van Eck HJ, Jacobs JME, van den Berg PMMM, Stiekema WJ, Jacobsen E: The inheritance of anthocyanin pigmentation in potato (Solanum tuberosum L.) and mapping of tuber skin colour loci using RFLPs. Heredity 1994, 73(4):410-421.

60. Chaim AC, Borovsky YB, De Jong WDJ, Paran IP: Linkage of the $A$ locus for the presence of anthocyanin and $f_{s} 10.1$, a major fruit-shape QTL in pepper. Theor App/ Genet 2003, 106(5):889-894.

61. Borovsky Y, Oren-Shamir M, Ovadia R, Jong W, Paran I: The A locus that controls anthocyanin accumulation in pepper encodes a MYB transcription factor homologous to Anthocyanin2 of Petunia. Theor Appl Genet 2004, 109(1):23-29.

62. De Jong WS, Eannetta NT, Jong DM, Bodis M: Candidate gene analysis of anthocyanin pigmentation loci in the Solanaceae. Theor Appl Genet 2004 108(3):423-432.

63. Bovy A, Schijlen $E$, Hall R: Metabolic engineering of flavonoids in tomato (Solanum lycopersicum): the potential for metabolomics. Metabolomics 2007, 3(3):399-412.

64. Gonzali S, Mazzucato A, Perata P: Purple as a tomato: towards high anthocyanin tomatoes. Trends Plant Sci 2009, 14(5):237-241.

65. Tatebe T: On inheritance of color in Solanum melongena L. Jpn J Genet 1939, 15(5):261-271.

66. Tigchelaar EC, Janick J, Erickson HT: The genetics of anthocyanin coloration in eggplant (Solanum melongena L.). Genetics 1968, 60(3):475-491.

67. Collard B, Jahufer $M$, Brouwer J, Pang E: An introduction to markers, quantitative trait loci (QTL) mapping and marker-assisted selection for crop improvement: the basic concepts. Euphytica 2005, 142(1):169-196.

68. Prohens J, Plazas M, Raigón M, Seguí-Simarro J, Stommel J, Vilanova S: Characterization of interspecific hybrids and first backcross generations from crosses between two cultivated eggplants (Solanum melongena and S. aethiopicum Kumba group) and implications for eggplant breeding. Euphytica 2012, 186(2):517-538.

69. Jannink J-L, Lorenz AJ, Iwata H: Genomic selection in plant breeding: from theory to practice. Brief Funct Genomics 2010, 9(2):166-177.

70. Tanksley S, Ganal M, Prince J, Devicente M, Bonierbale M, Broun P, Fulton T, Giovannoni J, Grandillo S, Martin G, Messeguer R, Miller J, Miller L, Paterson A Pineda O, Roder M, Wing R, Wu W, Young N: High density molecular linkage maps of the tomato and potato genomes. Genetics 1992, 132:1141-1160.

71. Bongue-Bartelsman M, Oneill SD, Tong YS, Yoder Il: Characterization of the gene encoding dihydroflavonol 4-reductase in tomato. Gene 1994, 138:153-157.

72. Zhang $Y$, Cheng S, Jong D, Griffiths H, Halitschke R, Jong W: The potato $R$ locus codes for dihydroflavonol 4-reductase. Theor Appl Genet 2009, 119(5):931-937.

73. Vogt T, Grimm R, Strack D: Cloning and expression of a cDNA encoding betanidin 5-O-glucosyltransferase, a betanidin- and flavonoid-specific enzyme with high homology to inducible glucosyltransferases from the Solanaceae. Plant J 1999, 19(5):509-519.
74. Mathews H, Clendennen SK, Caldwell CG, Liu XL, Connors K, Matheis N, Schuster DK, Menasco DJ, Wagoner W, Lightner J, Wagner DR: Activation tagging in tomato identifies a transcriptional regulator of anthocyanin biosynthesis, modification, and transport. The Plant Cell Online 2003, 15(8):1689-1703.

75. Gebhardt C, Ritter E, Barone A, Debener T, Walkemeier B, Schachtschabel U, Kaufmann H, Thompson RD, Bonierbale MW, Ganal MW, Tanksley SD, Salamini F: RFLP maps of potato and their alignment with the homoeologous tomato genome. Theor Appl Genet 1991, 83(1):49-57.

doi:10.1186/1471-2164-15-896

Cite this article as: Cericola et al:: Linkage disequilibrium and genome-wide association analysis for anthocyanin pigmentation and fruit color in eggplant. BMC Genomics 2014 15:896.

\section{Submit your next manuscript to BioMed Central and take full advantage of:}

- Convenient online submission

- Thorough peer review

- No space constraints or color figure charges

- Immediate publication on acceptance

- Inclusion in PubMed, CAS, Scopus and Google Scholar

- Research which is freely available for redistribution

Submit your manuscript at www.biomedcentral.com/submit
C) BioMed Central 